\title{
PENCIPTAAN KEUNGGULAN BERSAING UKM BATIK MELALUI PENERAPAN TEKNOLOGI PENGERING BATIK DAN DIGITAL MARKETING
}

\author{
Nugroho Mardi Wibowo ${ }^{1}$, Karsam $^{2}$, Yuyun Widiastuti ${ }^{3}$, Siswadi $^{4}$ \\ ${ }^{1}$ Universitas Wijaya Putra \\ ${ }^{2}$ Universitas Dinamika \\ ${ }^{3}$ Universitas Wijaya Putra \\ ${ }^{4}$ Universitas Wijaya Putra
}

nugrohomardi@uwp.ac.id, karsam@dinamika.ac.id, yuyunwidiastuti@uwp.ac.id, siswadi@uwp.ac.id

\begin{abstract}
Abstrak
Beberapa permasalahan UKM termasuk UKM Batik antara lain proses produksi masih menggunakan cara-cara tradisional dan keterbatasan dalam memasarkan produknya. Berangkat permasalahan tersebut kami melakukan kegiatan pengabdian masyarakat Program Pengembanganan Produk Unggulan Daerah pada mitra "Batik New Colet", Desa Jatipelem Kecamatan Diwek Kebupaten Jombang. Persoalan yang muncul pada setiap tahunnya terutama musim penghujuan adalah proses penjemuran memerlukan waktu lama bahkan tidak bisa kering karena hujan atau cuaca mendung dalam sehari. Kondisi ini akan memperlambat proses produksi dan menurunkan kualitas produk karena hasil pewarnaan berubah karena proses pengeringan tidak sempurna. Pada sisi pemasaran produk, mitra juga mengalami kendala karena hanya mengandalkan cara getok tular sehingga saat pandemi Covid-19, penjualan merosot tajam. Tujuan program ini adalah meningkatkan dan menjaga konsistensi kapasitas produksi serta mengurangi produk cacat pada proses pengeringan. Kedua, memperluas wilayah pemasaran serta mengembalikan dan meningkatkan trend penjualan seperti saat sebelum pandemi Covid-19. Metode program ini adalah perancangan dan pembuatan rumah oven batik, pelatihan dan pendampingan penggunaan rumah oven batik. Kedua, pelatihan dan pendampingan strategi pemasaran berbasis digital marketing. Program ini menghasilkan: 1) waktu proses pengeringan kain batik menjadi enam kali lebih cepat dan kapasitas produksi meningkat 22,25\%;2) produk tidak cacat meningkat menjadi 98\%; 3)penjualan meningkat sebesar 14,66\% dibanding tahun sebelumnya.
\end{abstract}

Kata Kunci :Rumah Oven Batik, Digital Marketing, Produk Cacat, Pandemi Covid-19, Batik Colet Jombang

\section{PENDAHULUAN}

Salah satu pilar pendukung perekonomian nasional adalah Usaha Mikro, Kecil dan Menengah (UMKM). UMKM memiliki sumbangsih yang cukup signifikan terhadap pereknomian nasional, disamping itu dapat mengurangi tingkat pengangguran dan kemiskinan. Salah satu sektor
UMKM yang berpotensi menjadi sektor yang unggul untuk menopang perekonomia Indonesia adalah industri kreatif batik.

Batik merupakan kekayaan seni dan budaya yang asli dari Indonesia. Kerajinan batik sudah lama dikenal oleh masyarakat dunia dan diakui oleh UNESCO sebagai cita karya asli Indonesia pada Sub tema Ekonomi,Sosial,dan Budaya 970 
tahun 2009. Hampir sebagian besar wilayah Indonesia, kabupaten dan kota memiliki motif batik khas daerah masing-masing (Wibowo et al., 2019).

Kabupaten Jombang merupakan salah satu daerah di Jawa Timur yang memiliki historis pengembangan batik,. Hal ini cukup beralasan mengingat Kabupaten Jombang adalah salah satu daerah peninggalan Kerajaan Majapahit. Pada tahun 1944 di Jombang muncul motif Batik Pacinan bermotif kawung dengan warna merah dan hijau. Batik Jombang kemudian hilang karena kesulitan mendapatkan bahan baku dan berkurangnya jumlah tenaga pembatik. Pada tahun 2006 Pemerintah Kabupaten Jombang 2006 mulai menggalakkan lagi pengembangan Batik Jombang. Inspirasi motif batik Jombang yang dikembangkan berasal dari salah satu relief Candi Rimbi peningggalan Kerajaan Majapahit yang di terletak Desa Ngrimbi Kecamatan Bareng Wonosalam Kabupaten Jombang. Jadilah motif Rimbi sebagai ciri khas motif batik Jombang disamping juga berciri khas motif-motif alam seperti motif bunga melati, tebu, cengkeh, pohon jati dan sebagainya. Strategi Pemerintah Kabupaten Jombang untuk mengembangkan usaha batik dan mengenalkan ke masyarakat dengan cara menggunakan batik bermotif khas Jombang (motif rimbi) pada pegawai Pemerintah Kabupaten Jombang dan pelajar di seluruh wilayah Kabupaten Jombang (Dyahwati et al., 2020).

Pada umumnya permasalahan yang dihadapi UMKM juga dialami oleh UMKM batik yaitu produksi, pemasaran, teknologi, dan sumber daya manusia (Andarwati et al., 2018). Para pengrajin batik di Kabupaten Jombang juga mengalami permsalahan yang sama dengan UMKM batik pada umumnya, termasuk permasalahan tersebut juga dihadapi oleh mitra program pengabdian kepada masyarakat ini.

Mitra program pengabdian kepada masyarakat ini adalah UMKM Batik Tulis New Colet yang dimiliki oleh Bapak Sutrisno. UMKM Batik New Colet beralamat di Dusun Pelem Desa Jatipelem Kecamatan Diwek Kabupaten Jombang. Berdasarkan analisis situasi dapat diidentifikasi beberapa permasalahan mitra. Persoalan yang muncul pada setiap tahunnya terutama musim penghujan adalah proses penjemuran memerlukan waktu lama bahkan tidak bisa kering karena hujan atau cuaca mendung dalam sehari. Kondisi ini akan memperlambat proses produksi dan menurunkan kualitas produk karena hasil pewarnaan berubah karena proses pengeringan yang tidak sempurna. Pada sisi pemasaran produk, mitra juga mengalami kendala karena hanya mengandalkan cara getok tular sehingga pada saat pandemi Covid-19 seperti saat ini, penjualan merosot tajam. Media pemasaran masih "getok tular" dan pemakaian media sosial dan website belum maksimal.

Dengan memperhatikan permasalahan tersebut, maka dapat dirumuskan tujuan program pengabdian kepada masyarakat ini. Pertama, meningkatkan kapasitas produksi dan mutu produk melalui pembangunan dan penerapan rumah oven batik. Kedua, meningkatkan penjualan melalui penggunaan digital marketing untuk memasarkan produk. Secara jangka panjang, diharapkan program ini akan memiliki outcome terhadap penciptaan daya saing UKM Batik Tulis New Colet.

Berkenaan dengan tujuan program pengabdian kepada masyarakat ini, maka dapat diberikan solusi untuk menyelesaikan permasalahan tersebut. Beberapa solusi yang ditawarkan kepada mitra adalah pembangunan dan penerapan rumah oven batik sebagai upaya meningkatkan kapasitas produksi dan kualitas produk. Kedua penggunaan digital marketing untuk memasarkan produk mitra guna meningkatkan penjualan.

\section{METODE}

Kegiatan pengabdian kepada masyarakat ini dilaksanakan mulai April sampai dengan September 2020. Kegiatan pengabdian tidak berhenti bulan September. Pada bulan Oktober sampai Nopember 2020, kegiatan diisi dengan aktivitas pendampingan dan menitoring.

Metode yang digunakan dalam kegiatan pengabdian kepada masyarakat ini adalah defusi ipteks berupa pembuatan dan penerapan Rumah Oven Batik Colet, Pelatihan dan Pendampingan penerapan Rumah Oven Batik Colet. Guna menyelesaikan permasalahan pemasaran, tim pelaksana metode pelatihan digital marketing. Sebagai kelanjutan pelatihan digital marketing

Sub tema Ekonomi,Sosial,dan Budaya 
adalah pendampingan penerapan digital marketing untuk memasarkan produk mitra.

\section{HASIL DAN PEMBAHASAN}

\section{Pembangungan dan Penerapan Rumah Oven Batik}

Metode difusi iptek dalam kegiatan pengabdian ini dilaksanakan melalui pembuatan rumah pengering kain batik sebanyak 1 unit dengan dimensi panjang 3 meter, lebar 3 meter dan tinggi 2,5 meter dengan kapasitas 20 potong kain batik per jam. Metode ini terdiri dari 3 (tiga) tahap yaitu perencanaan dan perancangan, pembangunan ruang pengering (oven) kain batik, pemasangan kompor, instalasi pipa pembuangan udara panas serta pemasangan pipa jemuran dan demo pengoperasian ruang oven batik serta serah terima ruang oven batik kepada mitra.

Perencanaan dan perancangan pembangunan ruang pengering (oven) batik colet diawali dengan menggambar desain ruang pengering batik colet, gambar perencanaan 3 (tiga) dimensi, dan perencanaan kebutuhan material. Desain ruang pengering batik dan gambar perencanaan tiga dimensi berguna untuk memudahkan pelaksana untuk membangun ruang pengering batik. Kegiatan mendesain ruang pengering batik dan menggambar tiga dimensi ruang pengering batik serta perencanaan kebutuhan kebutuhan materian dilakukan awal April 2020 sampai akhir April 2020.

Adapun pekerjaan tanah terdiri tiga jenis pekerjaan yaitu menggali tanah pondasi, menguruk tanah galian kembali, menguruk tanah peninggian lantai, dan menguruk pasir bawah pondasi. Pekerjaan dimulai awal Juni 2020 selama 1 (satu) minggu. Pekerjaan beton meliputi mengecor rabat beton lantai dengan tinggi $5 \mathrm{~cm}$, pembesian, pekerjaan beton, pekerjaan bekisting.

Pekerjaan dinding yang meliputi pemasangan bata dan memplester dinding dilakukan pada pertengahan Juni sampai dengan awal Juli 2020 dilanjutkan pekerjaan pembetonan dak cor sampai dengan bulan pertengahan Juli 2020 .

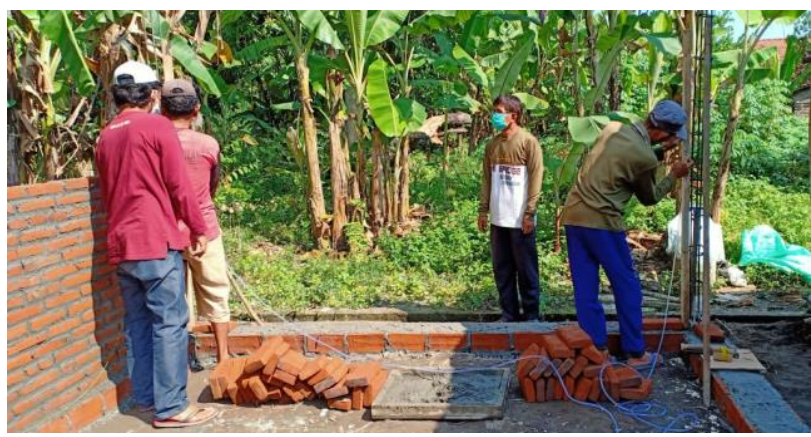

Gambar 1. Monitoring Pembangunan Rumah Oven Batik

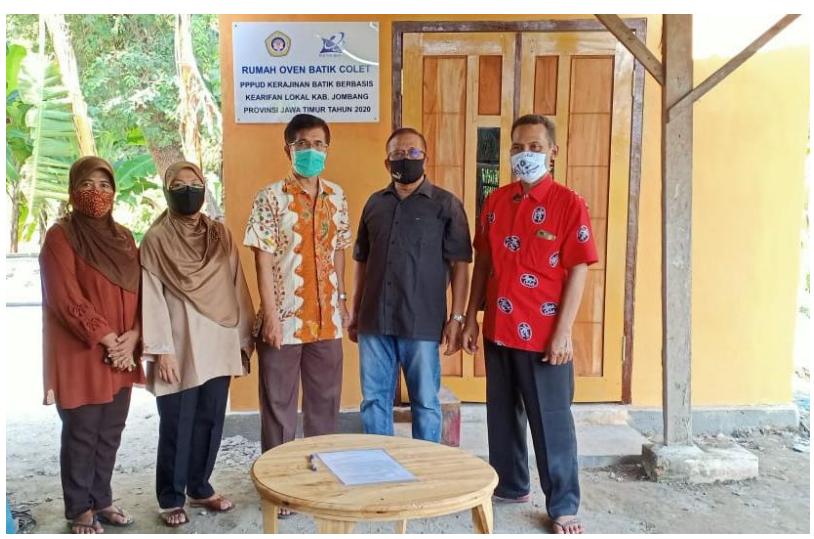

Gambar 2. Tim Pelaksana berpose di depan Rumah Oven Batik

\section{Pelatihan Cara Menggunakan Rumah Oven Batik}

Pelatihan cara penggunaan ruang oven batik kepada mitra, dimaksudkan agar mitra dapat memahami secara detil prosedur mengoperasikan ruang oven batik. Secara rinci mitra diharapkan dapat menghidupkan dan menentukan besaran api kompor yang digunakan, cara urutan menjemur kain di dalam ruang oven batik, melihat indikator suhu ruang oven batik, memahami aspek kesalamatan kerja bagi karyawan, dan termasuk memelihara ruang oven batik agar secara jangka tetap agar awet tetap digunakan.

Sub tema Ekonomi,Sosial,dan Budaya 


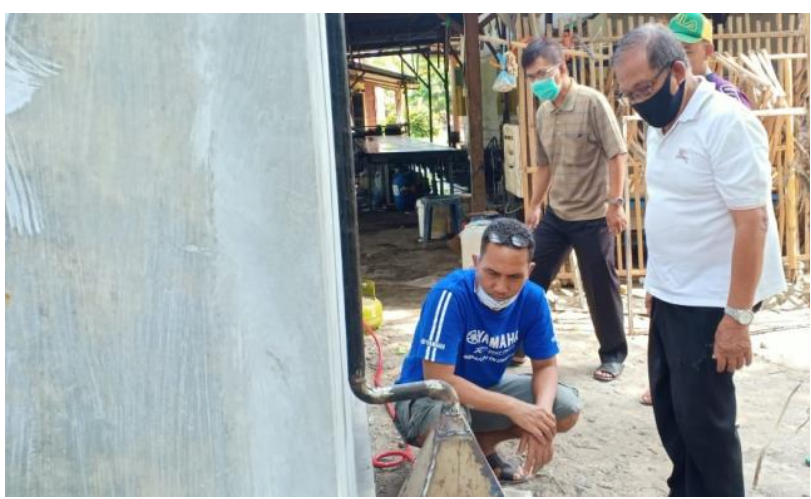

Gambar 3 Pelatihan Cara Penggunaan Ruang Oven Batik

\section{Pendampingan Penggunaan Ruang Oven Batik}

Pendampingan ruang oven batik kepada mitra, bertujuan agar mitra dapat menerapkan sambil praktek menggunakan Ruang Oven Batik. Kegiatan pendampingan penggunaan ruang oven batik meliputi menghidupkan dan menentukan besaran api kompor yang digunakan, cara urutan menjemur kain di dalam ruang oven batik, melihat indikator suhu ruang oven batik, menjaga aspek kesalamatan kerja dan termasuk memelihara ruang oven batik. Pandampingan penggunaan ruang oven batik dimulai awal Agustus 2020 dan selanjutnya akan dimonitoring setiap 2 (dua) minggu sekali.
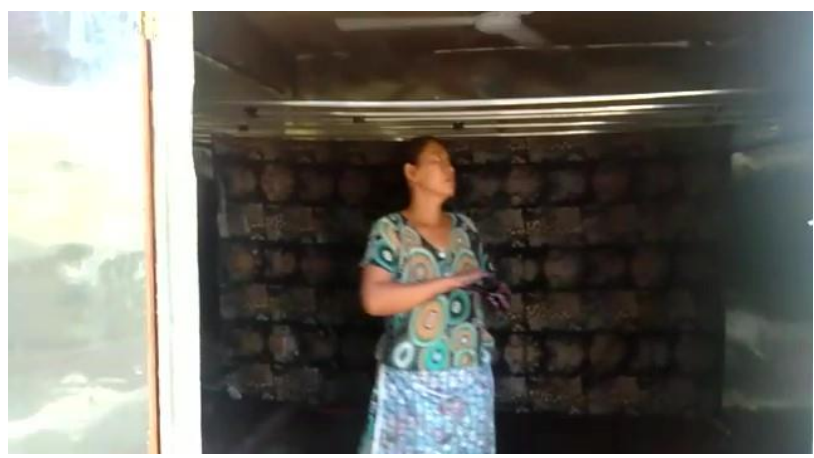

Gambar 3 Pelatihan Cara Penggunaan Ruang Oven Batik
Proses pengiringan kain batik pada saat hujan atau cuaca mendung akan tetap berjalan lancar dan bahkan lebih cepat dibandingkan dengan tahun sebelum-sebelumnya. Hal ini mengingat adanya pemakaian rumah oven batik colet untuk proses pengeringan pada musim penghujan atau cuaca mendung atau pemesan menginginkan pengiriman lebih cepat. Mesin oven batik colet dapat mengiringkan 20 potong kain batik per jamnya. Sehingga dalam sehari, mesin oven batik colet dapat mengiringkan sekitar 160 potong kain.

\section{Tabel 1}

Perbedaan Kecepatan dan Kualitas Hasil Pengeringan antara Penggunaan Sinar Matahari dan Rumah Oven Batik Colet

\begin{tabular}{|c|c|c|c|}
\hline No. & $\begin{array}{c}\text { Aspek } \\
\text { Pembeda }\end{array}$ & $\begin{array}{l}\text { Proses } \\
\text { Pengiringan } \\
\text { menggunakan } \\
\text { sinar matahari }\end{array}$ & $\begin{array}{l}\text { Proses } \\
\text { Pengiringan } \\
\text { menggunakan } \\
\text { Rumah Oven } \\
\text { Batik Colet }\end{array}$ \\
\hline 1 & $\begin{array}{l}\text { Proses } \\
\text { Pengeringan }\end{array}$ & $\begin{array}{l}\text { Mengandalkan } \\
\text { sinar matahari }\end{array}$ & $\begin{array}{lr}\text { Rumah } & \text { Oven } \\
\text { Batik } & \text { Colet. } \\
\text { Panas } & \text { berasal } \\
\text { dari } & \text { udara } \\
\text { kompor gas. }\end{array}$ \\
\hline \multirow[t]{2}{*}{2} & \multirow[t]{2}{*}{$\begin{array}{l}\text { Waktu } \\
\text { Pengeringan }\end{array}$} & $\begin{array}{l}6 \text { jam (cuaca } \\
\text { cerah) }\end{array}$ & \multirow[t]{2}{*}{1 jam } \\
\hline & & $\begin{array}{l}2 \text { hari (cuaca } \\
\text { hujan } \\
\text { mendung) }\end{array}$ & \\
\hline \multirow[t]{2}{*}{3} & \multirow[t]{2}{*}{ Kapasitas } & $\begin{array}{l}20 \text { potong kain } \\
\text { / hari (cuaca } \\
\text { cerah }\end{array}$ & \multirow[t]{2}{*}{$\begin{array}{l}20 \text { potong / jam } \\
\text { atau } \\
160 \text { potong / hari }\end{array}$} \\
\hline & & $\begin{array}{l}10 \text { potong kain } \\
\text { / hari (cuaca } \\
\text { hujan } \\
\text { /mendung) }\end{array}$ & \\
\hline 4 & Kualitas & $\begin{array}{l}\text { Hasil } \\
\text { pewarnaan ada } \\
\text { noda (terutama } \\
\text { pada musim } \\
\text { hujan/ } \\
\text { mendung) }\end{array}$ & $\begin{array}{l}\text { Tidak ada noda, } \\
\text { kualitas menjadi } \\
\text { sempurna. }\end{array}$ \\
\hline
\end{tabular}

Kehadiran teknologi rumah oven batik colet tidak bisa dipungkiri berdampak terhadap peningkatan keberdayaan mitra dalam peningkatan

Sub tema Ekonomi,Sosial,dan Budaya 
kapasitas produksi batik. Berdasarkan perhitungan tim pelaksana dan UKM mitra, didapat hasil bahwa ada peningkatan peningkatan kapasitas produksi sebesar 22,25\% dibandingkan tahun 2019. Dengan pemakaian rumah oven batik colet, proses pengeringan kain batik akan berjalan lancar dan cepat, tidak terkendala dengan sinar matahari pada musim penghujan atau cuaca mendung. Dengan peningkatan kapasitas produksi batik, diharapkan akan berdampak pada pemenuhan permintaan batik yang semakin lama mengalami trend peningkatan terutama pada saat pandemi COvid-19 sudah mulai berkurang.

Keberadaan rumah oven batik colet memeliki peran yang sangat penting baik untuk meningkatkan kapasitas produksi dan kualitas produk. Dengan adanya rumah oven batik colet, mitra tidak lagi menemui kendala lagi dalam proses pengeringan terutama pada cuaca hujan atau mendung. Dalam cuaca hujan atau mendung mitra kerap kali menemui produk cacat terutama pada hasil pewarnaan yang kurang sempurna dan ada noda. Hal ini disebabkan oleh proses pengeringan yang tidak sempurna pada cuaca hujan atau mendung. Sejak rumah oven batik colet digunakann oleh mitra, kendala tersebut tidak lagi terjadi bahkan kualitas dan hasil pewarnaannya menjadi sempurna. Tingkat produksi tidak cacat meningkat dari sebelumnya $95 \%$ menjadi $98 \%$.

\section{Pelatihan dan Pendampingan Digital Marketing}

Pelatihan Strategi Pemasaran Berbasis Website dan Media Sosial (Digital Marketing) bertujuan untuk memberikan pengetahuan kepada mitra tentang bagaimana keberadaan website dan media social dapat digunaka untuk memasarkan produk batik. Dalam pelatihan tersebut pelaksana PPPUD menjelaskan kepada mitra bahwa website dan media social dapat membantu mitra dalam memasarkan produknya dengan menjangkaau wilayan pasar yang luas dan menghemat biaya pemasaran. Dalam digital marketing, mitra dapat menjali komunikasi dengan konsumen dan calon konsumen serta memperluas jaringan bisnis. Tim pelaksana juga menyampaikan kepada mitra bahwa pada media social mitra dapat mengupload foto produk dan memberikan deskripsi produk serta mendapatkan peluang untuk menciptakan merek (branding). Penggunaan media social dapat meningkatkan responsivitas calon konsumen untuk memberikan penilaian produk dengan mengklik baik menyukai maupun tidak menyukai. Pelatihan Strategi Pemasaran berbasis Website dan Media Sosial dilaksanakan pada tanggal 5 Juli 2020 dan selanjutnya dilakukan pendampingan setiap satu atau dua minggu sekali.

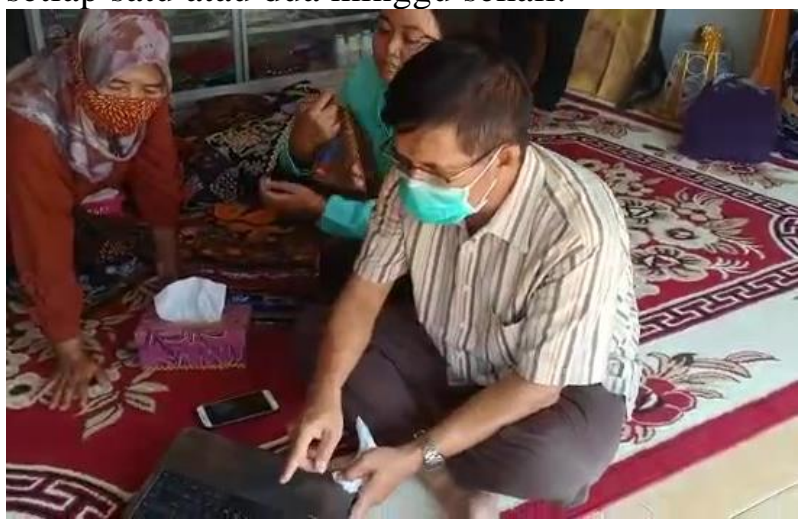

Gambar 4. Pendampingan Pemasaran Digital

Dengan pelatihan dan pendampingan pemasaran berbasis digital marketing serta penerapan Teknologi Tepat Guna (TTG) Rumah Pengering (Oven) Batik Colet, kegiatan PPPUD ini memiliki dampak terhadap positif terhadap peningkatan omset. Terhitung mulai Maret 2020 sampai dengan laporan kemajuan ini disusun (pertengahan Agustus 2020) pandemi Covid-19 melanda seluruh dunia termasuk di Indonesia. Pandemi covid-19 tersebut sangat terasa dampaknya terhadap kelangsungan bisnis dan penjualan mitra. Berdasarkan data keuangan mitra, diperoleh bahwa mulai bulan Februari sampai dengan Juni 2020 omset mitra mengalami penurunan $1 \%$, namun pada bulan Juli 2020, bisnis batik mitra menggeliat kembali. Tercatat sampai dengan bulan Juli 2020 ada kenaikan omset sebesar 2,94\% dibandingkan bulan Juni 2020. Pada bulan Juli 2020 mitra memperoleh omset sebesar Rp. 35.755.600,-. Omset bulan Juli 2020 masih lebih tinggi dari bulan Desember 2019.

Sub tema Ekonomi,Sosial,dan Budaya 974 


\section{KESIMPULAN}

Kegiatan pembangunan Rumah Oven Batik Colet, pelatihan dan pendamping pengoperasian rumah oven batik colet akan berdampak pada peningkatan kapasitas produksi dan kualitas produk. Ada peningkatan kapasitas produksi sebesar 22,25\% dibandingkan dengan tahun sebelumnya. Pewarnaan batik menjadi lebih baik dan tidak ada noda Produk tidak cacat meningkat menjadi $98 \%$.

Kegiatan pelatihan dan pendampingan digital marketing memiliki peran penting dalam memperkenalkan produk, memperluas wilayah pasar dan meningkatkan kepercayaan konsumen. Keberadaan website memiliki dampak terhadap pengenalan produk dan perluasan pasar.Adanya peningkatan kualitas produk batik.

Omset mitra berkecenderungan mengalami penurunan pada periode bulan Januari sampai dengan Juni 2020 karena Pandemi Covid-19. Mulai bulan Juli 2020 omset mitra mengalami kenaikan sebesar 2,94\% dibandingkan bulan Juni 2020 dan tren penjualan mulai mengalami peningkatan. Dengan demikian dapat diprediksi peningkatan omset mitra pada tahun 2020 sebesar 14,66\% dibandingkan dengan tahun 2019.

\section{UCAPAN TERIMAKASIH}

Ucapan terimakasih disampaikan kepada Direktur Riset dan Pengabdian Masyarakat Deputi Bidang Penguatan Riset dan Pengembangan Kementerian Riset, dan Teknologi / Badan Riset dan
Inovasi Nasional yang membiayai kegiatan Pengabdian kepada Masyarakat skema Program Pengembangan Produk Unggulan Daerah (PPPUD). PPPUD tahun 2020.

\section{REFERENSI}

Andarwati, M., Subiyantoro, E., \& Subadyo, T. (2018). Pengaruh Pelatihan dan Penerapan Teknologi Tepat Guna (TTG) Terhadap Keberdayaan Pengrajin Batik Tulis Ramah Lingkungan. Briliant: Jurnal Riset Dan Konseptual, $\quad 3(3), \quad 280$. https://doi.org/10.28926/briliant.v3i3.189

Dyahwati, W., Lodra, I. N., \& Supranto, H. (2020). TRANSFORMASI CANDI RIMBI DALAM MOTIF BATIK SEBAGAI EDUKASI BUDAYA LOKAL KABUPATEN JOMBANG. Haluan Sastra Budaya, 4(1), 2020.

https://jurnal.uns.ac.id/hsb/article/view/40867

Wibowo, N. M., Karsam, K., Widiasuti, Y., \& Siswadi, S. (2019). EMPOWERMENT OF BATIK SMES THROUGH DEVELOPMENT OF LOCAL WISDOM BASED MOTIF DESIGN: EFFORTS TO BUILD BRAND IMAGE OF BATIK JOMBANG. Jurnal Sinergitas $P k M \quad \& \quad C S R, 4(1), 1-10$. https://ojs.uph.edu/index.php/JSPC/article/vie w/2094 